\title{
The linguo-regional knowledge aspect of the structure of the teaching methodology of Russian as a foreign language as one of the ways of adaptation of foreign students
}

\author{
Elena Gagarina, Ksenia Gushchina, and Anna Matyushkova \\ Astrakhan state medical University, Astrakhan, Russia
}

\begin{abstract}
The present article touches upon the problems of adaptation of foreign students in the multicultural region of Russia - the Astrakhan oblast. The article outlines the main methodological ways of solving them in the framework of education by updating the linguo-regional knowledge aspect of the structure of the teaching methodology of Russian as a foreign language (RFL), and gives descriptions of methodological models for the implementation of linguocultural adaptation of foreign students in the process of educational activities of the university based on the linguoregional specifics of the region. This work reveals the significance of the regional component of the RFL methodology aimed at forming communicative skills and abilities of students, in order to intensify the adaptation process. The authors present the features of country-specific and linguo-regional studies carried out in classroom and extracurricular time at the Department of Russian Language of Astrakhan State Medical University. The authors of the article associate the effectiveness of the adaptation process and acculturation of foreign students with the actualization of the linguo-regional knowledge aspect of the structure of the RFL methodology, which contributes to the formation of internal motivation for learning the Russian language and getting acquainted with Russia, to the removal of psychological communication barriers and to the development of communication skills. This work suggest using the principles of consistency and concentrism in the formation of countryspecific and regional knowledge, ensuring the reliability of visual information, and taking into account the native culture of foreign students with semantisation of words with a cultural component.
\end{abstract}

\section{Introduction}

In the modern world, an integrated international educational space implies the creation of conditions and opportunities for studying abroad anywhere in the world in order to obtain higher professional education. The focus of higher education institutions on the internationalization of their educational activities is becoming a priority task and a strategy of major importance. At the same time, it is important to remember that the adaptation of foreign citizens takes place in the conditions of educational activity, which is the main task for them. In this regard, the problem of adaptation of foreign students to the conditions of a 
new cultural environment for them is actualized, which is especially important for the Astrakhan region as a multicultural region. The problems of compatibility of different cultures, interreligious contacts within one region require a special approach to the adaptation in the structure of the higher education system [9].

Currently, the methodology of teaching foreign languages associates the effectiveness of teaching with the formation, first of all, of intercultural communication skills (Kostomarov V.G., Furmanova V.P.), of the linguo-cultural erudition of students (Prokhorov Yu.E., Chernyavskaya T.N., Otmenitova O. M.), as well as development of a tolerant attitude and behavior (Elizarova G.V., Ivanova E.G.) which is especially important for the educational process of teaching foreign students in a specific language environment.

The development of linguo-regional studies as a science occurred in the 20 s of the XX century. In the methodology of teaching RFL, the problem of the relationship between language and culture was initially reflected in the theory of linguistic and regional studies, the foundations of which were laid in the works of E.M. Vereshchagin and V.G. Kostomarov.

Regional speech material has a centuries-old history, it conveys certain features of national life, and is a cultural heritage reflected in folklore, having oral and written language canons, as well as various forms of existence: dialects, spoken language, national literary language.

Having considered a number of definitions of the concept of "linguo-regional studies", we settled on the following statements:

For example, the definition of K.D. Ushinsky, who believes that the study of the history of the native land is done through the facts of the language, because in "the whole people and all their homeland are spiritualized in the language, as well as the whole history of spiritual life" [1, pp 106-107];

However, L.A. Klimkova understands linguo-regional studies as "the study of the linguistic component of the life of the region, along with the study of its natural and climatic, historical and archaeological, ethnographic and other features" [2, p.94];

E.A. Ogneva's opinion reveals this concept even more broadly, assuming that in the broad sense of the word, it is a scientific direction that interprets the features of the foreign verbalization of traditions, history and culture, the characteristics of nature and the population of any particular part of the country, region; in the narrow sense of the word linguistic studies is a curriculum discipline, which includes the process of learning a foreign language, with the aim of forming foreign linguistic and regional communicative competencies and strategies" [6, pp.75-76].

In this work, we give the following definition of the concept of linguo-regional studies": linguo-regional studies is the familiarization of students with the traditions, history and culture of a particular part of the country in the process of language education, that is, through the facts of language, in order to form communicative skills and linguo-regional competence. The regional aspect involves the study of the dialectal varieties of the host language, the peculiarities of geographical and personal names, acquaintance with the language of regional folklore and the works of local writers.

The authors, following the researchers (E.M. Vereshchagin, D. B. Gudkov, A. A. Zaliznyak, Yu. N. Karaulov, V. G. Kostomarov, O.D. Mitrofanova, Yu. E. Prokhorov, Yu. S Stepanov, L.I. Kharchenkova, A.D. Shmelev and others), believe that linguo-regional studies have undoubted didactic potential, which in the context of the education will boost the learning process, activate the cognitive interest of students, create a positive emotional background of learning and facilitate the adaptation.

In many Russian universities, especially regional ones, there is a need to create textbooks that reflect local features. Such a need also exists at the Astrakhan State Medical University, where the number of foreign students from Egypt, Morocco, Tunisia, Namibia, 
Botswana and other states has significantly increased. For example, in 2020, at the Department of Russian Language, a textbook on the development of speech for foreign students "Welcome to Astrakhan" was published, which gets them acquainted with nature, culture, history, outstanding people of the Astrakhan region, and the sights of the city. It is important to note that the textbook is designed both for classroom work with a teacher and for independent use [5].

In education of foreign students, in order to increase the efficiency of language acquisition, when creating textbooks that reflect the regional component, it is necessary to adhere to the following principles:

a) the principle of dialogue between cultures and civilizations;

b) the principle of didactic cultural conformity;

c) the principle of domination of methodologically acceptable problematic cultural tasks $[4, \mathrm{p} .240]$.

\section{Materials and methods}

Linguo-regional studies in the lessons of RFL is aimed both at teaching the language and the formation of basic knowledge and ideas about Russia, Russian culture and history, and at developing communication skills in foreign students in the process of intercultural communication. If language education is a synthesis of educational, cognitive, developmental and disciplinary components, then national and linguo-regional knowledge should be used not only when teaching Russian language to foreign students in the Russian language classes, but also in the process of extracurricular educative activities. The main educational goal of foreign citizens studying in Russia is free communication in the new socio-cultural environment and in professional activities. Therefore, when teaching RFL, it is necessary to demonstrate to students the use of the Russian language in all basic communicative situations based on real life facts. Understanding the language and the ability to use it as a means of communication is possible only after familiarization and assimilation of linguocultural phenomena common to the region. The use of national and regional studies material in the process of educational work with foreign students contributes to the formation of their motivation to further study of Russian as a foreign language, as well as to the quick and successful adaptation of foreigners to Russian realias.

Thus, the purpose of this work is to consider the influence of the linguo-regional knowledge aspect of the structure of teaching RFL on the speed of adaptation to a foreign cultural environment.

\section{Results and discussion}

The effectiveness of language learning of foreign citizens in a foreign language environment, according to methodologists and teachers, depends on "taking into account the laws of adaptation of the individual to the educational conditions" [1]. The factors influencing the successful mastering of a foreign language and the speed of integration into a new cultural environment include the active implementation of the methodological model of linguocultural adaptation of foreign freshmen, which is carried out in parallel with educational activities. The process of executing the integrative adaptation model, according to the authors of this article, should involve the regional component of the methodology for teaching Russian as a foreign language.

The process of acculturation, which consists in changing the patterns of one cultural group to another as a result of a long stay in a different cultural environment, is performed through language and communication. By "communication" the authors of the article mean 
a wide range of direct interaction not only with native speakers of another language, but also with linguocultural phenomena of reality that are new for a foreign student. With a common mental modality for all regions of Russia, each region has its own unique ethnocultural environment. The historically multicultural Astrakhan region is distinguished by special interest and complexity of perception (especially for a representative of a different sociocultural affiliation): the mixing of different ethnic groups, traditions and languages complicates the adaptation of foreign students.

We find the opinion of the discoursologist Yu.E. Prokhorov interesting. He believes that "any communication is carried out in a specific form of manifestation of reality - its reality, which determines the choice of certain conditions and means of communication [2]. That is, taking into account the totality of the realias of a particular region, called the "landscape of reality", is important not only for introduction into the environment, but also for the formation of an active thesaurus covering not only the vocabulary of a particular language in its entirety according to the educational standard, but also the vocabulary of this region.

Following N.V. Pomortseva, who distinguishes the following types of adaptive activities: everyday, climatic, physiological, socio-cultural, psychological, didactic, etc., we, within the framework of the research topic, consider these types as the most important: everyday, climatic, and socio-cultural types.

1. Everyday adaptation. The peculiarity of this type of adaptation of foreign students lies in the successful functioning in the host society, the development of norms and rules of behavior different from their usual way of life, associated with the peculiarities of living in a foreign socio-cultural environment, as well as from some elements of the life of their native culture, which may not fit or even be indecent in the foreign cultural field of the new country. Therefore, it is important to understand what difficulties and contradictions foreign students are facing on their way towards integration into the environment. So, the everyday form of adaptation implies continuous daily communication with native speakers, and this requires overcoming the psychological barrier and loosening the established static stereotypes of behavior firmly fixed in the minds of foreigners. For this reason, in many universities, it is customary to carry out the accommodation of foreign students on the basis of cultural differences. From the point of view of Russian language teaching, it is necessary to introduce into the content of the educational process some lexical units that reflect and characterize the general cultural context of the Astrakhan region. The study of regional literary and journalistic texts plays a significant role in understanding the local image of the world. Regional literature represents to students a certain linguistic model of culture not only of a particular area, but also of the country as a whole. Such deep work with the language of a piece of art contributes to the emotional assimilation of the values of a different environment, and removes speech, communicative and psychological barriers in talking.

In addition, in the main regional universities, educational activities involve organizing student events in order to optimize the adaptation process, and to create favorable conditions for intercultural communication of students. For example, foreign students of the Astrakhan State Medical University are happy to take part in the events dedicated to the National Unity Day: they are attracted by the variety of folk costumes, the peculiarities of the national cuisine of the ethnic groups living in the region. The university also hosts events where foreign students can present their cultural traditions and customs: "Africa Day", "Morocco Day", "Tunisia Day", "Train of Friendship", etc. As a result of the regionoriented work of the teacher, the foreigner accumulates in his mind nominative units that contribute to the correlation of the attributes, objects and images of the Russian regional life with the native ethnic and cultural specifics of the foreigner. For example, dialectisms: kainary are small-sized belyash that are usually prepared by Tatar housewives for the holidays; tarashka - the local name for taranka (silver bream); bersh is a type of 
actinopterygian perches, similar to small pike perch; yerik is a relatively narrow channel connecting lakes, bays, channels or river arms to each other, usually in the lower Volga; ilmeni - freshwater lakes, mainly concentrated to the west of the delta; televizor - is the popular name for fishing tackle; tutnik/tutovnik, mulberry (trees, a crop with a rich harvest of delicious berries and many useful properties); to dive bashem - headfirst; kildim - a gathering, a meeting of a group of persons; demyanki - eggplants in the south and North Caucasus; chikhvostit - to scold; beshbarmak - a traditional meat and flour dish of the Turkic-speaking peoples; viziga, vyaziga - the name of the eatable chorda of sturgeon fish; karakurt - a species of black widow spider found in the desert and steppe zone.

2. Climatic adaptation is a very important part of the adaptive activity of the human body. The continental climate of the Astrakhan region is strikingly different from the weather conditions of the native countries for foreign students; most of the students are completely unprepared for living in a colder climate. There are the following symptoms of acclimatization: decreased appetite, sleep disturbance (insomnia or constant drowsiness), decreased immunity, dullness, weakness, loss of working capacity, water-salt balance disturbance, low/high blood pressure, headaches, dizziness, indigestion (nausea, vomiting, diarrhea, constipation), shortness of breath, skin rashes and others. Physiological changes will inevitably affect the psychological state of the student, which, in turn, will entail a decrease in educational motivation. As practice shows, most often the acclimatization process is accompanied by a sharp deterioration in the state of the immune system, which results in both chronic and temporary diseases aggravation. This, in turn, affects academic performance and general well-being in the new country. In this regard, the importance of mastering the vocabulary of the thematic groups "weather", "seasons", "diseases", and also a large part of the semantic and phraseological potential of lexemes included in these groups, becomes relevant. So, the process of adapting to a new climate through acquaintance with the corresponding new words and word images produces an introduction into the active lexical composition of words and their semantic (phraseological, idiomatic) variants in a wide stylistic range, describing the features of the climatic conditions of the region (for example: mud/slush, sea breeze, wind/storm, cold/bone-chilling cold, hot weather/heat/stuffiness); nominative features of clothing items and accessories, as well as adjective vocabulary as a tool for mental and cultural enrichment. Classes focused on the seasonal characteristics of the climate of the Astrakhan region (including lessons in the open air), correction of the content of educational activities and the inclusion of lexical material in it, synthesizing the process of perception of the "landscape of reality" and verbalization of thoughts and feelings. Students are invited to study extensive lexical material that reflects the climatic situation of the Astrakhan region: nouns season, blizzard, snowdrifts, puddles, drought, thunderstorms, sunrise, sunset, adverbs dirty, stuffy, hot, phrases to dress according to the weather, to ski, to sled, to ice skate, to snowboard, to make a snowman, to play snowballs, temperature changes, the wind blows, blows in the face, blows in the back, wind from the sea, rain and snow, comes in flakes, "Indian summer", "golden autumn", adjectives sunny, cloudy, damp, rainy, warm, windy, cold, frosty, clear. In addition, in the learning process, such idiomatic expressions with the word wind as "wind in the head", "throw money down the wind", "where the wind blows", "taken by the wind", "have the nose to the wind" are considered. In the process of mastering the lexical layer of words of the above group, a foreign student forms in his mind a certain idea of the country and region of residence, its climatic characteristics, acquires the skills of expressing his state.

3. Sociocultural adaptation suggests intensive mastering of language and speech competencies through the organization and conduct of extracurricular cultural events: excursions to the cultural places of the city, visits to museums and theaters. The effectiveness of this form of lexico-oriented work with students lies, in the first place, in 
preliminary preparatory work. The teacher offers a short history background, limited by the topic of the event, introduces the necessary lexical context, allowing them to expand their vocabulary and immerse in the local history. There are many places and objects of cultural heritage in the city of Astrakhan and the Astrakhan region: the Kremlin, the Drama Theater, the Opera and Ballet Theater, Art galleries, house-museums, etc. In addition, the historically and geographically conditioned multiculturalism of the Astrakhan region presupposes the holding of events with the participation of the main ethnic groups of the region, which also has a great linguo-regional potential in terms of adaptation to a new cultural environment. At the same time, it is important to pay attention not only to the study of texts of the corresponding content, but also to the emotional involvement of the student. In this regard, visual support of the information already available is necessary. According to E.M. Vereshchagin and V.G. Kostomarov "cultural adaptation presupposes not only a rational understanding of a certain fact, but also its emotional experience." Indeed, the empirical way of knowing the reality of a foreign culture is important for psychological emancipation and a sense of personal involvement in a specific location and ethnicity.

In the course of any extracurricular work, foreign students enter into live communication with representatives of Russian culture in its special regional form. This communicative practice contributes not only to the consolidation of speech patterns of behavior, but also allows to successfully practice the regional knowledge aspect in the teaching methodology of RFL. Integration of foreigners into the system of established social relations, contributes to the formation of speech competencies of students, familiarization and consolidation of etiquette norms of behavior, increases motivation to learn the language.

\section{Conclusion}

Linguo-regional education carried out among foreign students in the framework of the educational process with a focus on the regional component in the RFL methodology forms the skills of intercultural communication, helps to remove and eliminate psychological barriers associated with a foreign cultural environment, contributes to the intensification of the adaptation process, broadening the students' outlook and their notion on the regional and national mentality of Russians, which contributes to the full mastery of the language. The presence of linguo-regional knowledge aspect in the structure of the methodology of teaching Russian as a foreign language helps in the development of such personal qualities of a foreign student as communication skills, culture of communication, tolerance, commitment, ability to cooperate, responsibility, independence, creative activity; in the formation of intellectual and cognitive abilities, in particular, the ability and readiness for independent and continuous study of a foreign language, for further self-education with its help; as well as in progression in the experience of productive creative activity, gaining experience in research activities using the studied language.

\section{References}

1. F. I. Buslaev, Preface to the "Experience of the historical grammar of the Russian language." (1858)

2. E.M. Vereshchagin, V.G. Kostomarov, Language and Culture: Linguistic and Regional Studies in Teaching Russian as a Foreign Language (1990)

3. L. A. Klimkova, Bulletin of the Kostroma State University named after N. A. Nekrasov, 92 (2017) 
4. A. I. Matyushkova, The role of the dialogue of cultures in the lessons of Russian as a foreign language, Materials of the VII scientific-practical conference of students and young scientists with international participation, 238 (2019)

5. Zh. Yu. Motygina, L.N. Yusupalieva, N.A. Filatova, Welcome to Astrakhan (2020)

6. E. A. Ogneva, Bulletin of the Kirghiz-Russian Slavic University, 1, 74(2018).

7. Yu. E. Prokhorov, Reality. Text. Discourse (2004)

8. N. V. Pomortseva. Russian language abroad, 2, 35 (2010).

9. A.Kh. Satretdinova, Z.P. Penskaya, Revista Dilemas contemporaneos: Educacion, Politica y Valores (2019),

http://www.dilemascontemporaneoseducacionpoliticayvalores.com/ 